\title{
$\mathrm{TCNQ}$ 분자를 이용한 유기 발광 소자의 전기적 특성
}

\author{
나수환 ${ }^{1}$, 김태완 ${ }^{1, a}$ \\ ${ }^{1}$ 홍익대학교 정보디스플레이공학과
}

\section{Electrical Properties of Organic Light-emitting Diodes Using TCNQ Molecules}

\author{
$\mathrm{Su}-\mathrm{Hwan} \mathrm{Na}^{1}$ and $\mathrm{Tae}-\mathrm{Wan} \mathrm{Kim}^{1, \mathrm{a}}$ \\ ${ }^{1}$ Department of Information Display Engineering, Hongik University, Seoul 121-791, Korea
}

(Received May 7, 2010; Revised October 15, 2010; Accepted October 19, 2010)

\begin{abstract}
Electrical properties of organic light-emitting diodes were studied in a device with 7,7,8,8-tetracyano-quinodimethane (TCNQ) to see how the TCNQ affects on the device performance. Since the TCNQ has a high electron affinity, it is used for a charge-transport and injection layer. We have made a reference device in a structure of $\operatorname{ITO}(170 \mathrm{~nm}) / \operatorname{TPD}(40 \mathrm{~nm}) / \mathrm{Alq}_{3}(60 \mathrm{~nm}) / \mathrm{LiF}(0.5 \mathrm{~nm}) / \mathrm{Al}(100 \mathrm{~nm})$. And two types of devices were manufactured. One type of device is the one made by doping 5 and 10

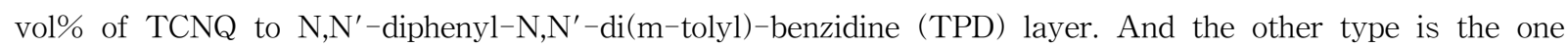
made with TCNQ layer inserted in between the ITO anode and TPD organic layer. Organic layers were formed by thermal evaporation at a pressure of $10^{-6}$ torr. It was found that for the TCNQ doped devices, turn-on voltage of the device was reduced by about $20 \%$ and the current efficiency was improved by about three times near $6 \mathrm{~V}$. And for devices with TCNQ layer inserted in between the ITO anode and TPD layer, it was found that the current efficiency was improved by more than three times even though there was not much change in turn-on voltage.
\end{abstract}

Keywords: Organic light-emitting diodes, TCNQ, Electrical properties

\section{1. 서 론}

Tang과 VanSlyke는 1987년에 낮은 구동 전압과 고효율의 유기 전기 발광 구조를 보고하였으며, 이후 유기 발광 소자는 평판 디스플레이 산업에 있어서 많 은 발전을 해왔다 [1]. 유기 발광 소자에 있어서 구동 전압, 소비 전력, 그리고 발광 효율은 중요한 특성들 이다. 특히 낮은 구동 전압과 낮은 소비 전력의 소자 를 구현하기 위해서는 양전극과 음전극에서 전하 수 송층으로의 원활한 전하 주입과 수송층에서의 전하 이동도가 향상되어야 한다. 따라서 전하 주입과 수송

a. Corresponding author; taekim@hongik.ac.kr
은 소자 성능에 큰 영향을 미치게 되어, 적절한 제어 를 통해 효율적인 유기 발광 소자의 설계가 요구된다. 현재까지 전하 주입과 수송을 향상시킨 다양한 구 조 및 재료들이 제안되고 있다. Tang과 VanSlyke는 aromatic diamine과 tris (8-hydroxyquinoline) aluminium $\left(\mathrm{Alq}_{3}\right)$ 의 유기 반도체를 사용한 이중층의 구조를 이용하여 낮은 구동 전압과 고효율의 소자를 구현하였다 [1]. 이러한 다층 구조의 소자 구조 뿐만 아니라, 유기물을 도핑하여 소자의 성능을 개선하기 도 한다. 도핑을 하면, 다음과 같은 효과를 얻을 수 있다. 첫째로 옴성 전도도가 형성되어 두꺼운 수송층 이라 할 지라도 수송층에서의 전압 강하를 낮출 수 있고, 둘째로 옴성 접촉 근처의 도핑 준위를 높임으 
로 인해 형성된 얇은 공간 전하층은 터널링에 의한 전하 주입을 효과적으로 할 수 있도록 해준다 [2,3].

2001년 Zhou 연구팀은 정공 수송층에 도핑을 함으 로써 정공 주입을 향상시키는 연구를 하였다 [4]. 정 공 수송층으로 2,3,5,6-fluoro-7,7,8,8-tetracyano-quino dimethane $\left(\mathrm{F}_{4}-\mathrm{TCNQ}\right)$ 을 도핑한 $4,4^{\prime}, 4^{\prime \prime}-$ tris $(N, N$-diphenyl-amino) triphenylamine (TDATA)을 사용하였다 [4]. 그 결과 정공 수송층의 높은 전도도 와 전하 운반자의 전하 밀도를 제어할 수 있었다 [4]. $\mathrm{TCNQ}^{-}$유도체는 $\mathrm{p}^{-}$형 도펀트로서 방향족기인 시아 노기 (cyano-group : $\mathrm{CN}$ )와 결합하고 있어서 강한 전자 끌게 특성을 가진다. 이 물질을 정공 수송층에 이용하게 되면, 유기물층의 전도도가 향상되어 소자 의 특성이 향상된다 [5].

본 연구에서는 낮은 구동 전압과 고효율의 소자를 구현하기 위하여, 정공 수송층으로 사용되는 $\mathrm{TPD}$ 에 7,7,8,8-tetracyano-quinodimethane (TCNQ)을 도핑하 거나 $\mathrm{ITO}$ 와 $\mathrm{TPD}$ 사이에 박막층으로 삽입하여 소자 를 제작하였다. 이들의 전기적 특성과 $\mathrm{TCNQ}$ 에 의한 효과를 분석하였다.

\section{2. 실험 방법}

기본 소자는 $\operatorname{ITO}(170 \mathrm{~nm}) / \mathrm{TPD}(40 \mathrm{~nm}) / \mathrm{Alq}_{3}(60$ $\mathrm{nm}) / \mathrm{LiF}(0.5 \mathrm{~nm}) / \mathrm{Al}(100 \mathrm{~nm})$ 의 구조로 만들었다. 양 전극으로 사용한 indium-tin-oxide (ITO) 전극의 두 께는 $170 \mathrm{~nm}$ 이고 면저항은 $10 \Omega / \mathrm{sq}$ 이며, Asahi Co. 로부터 구입하였다. ITO 기판의 크기는 $2 \times 2 \mathrm{~cm}^{2}$ 로 하였으며, $3 \mathrm{~mm}$ 의 폭으로 패터닝을 하였다. 패터닝 방법은 질산과 염산을 $3: 1$ 로 섞은 용액을 이용하여 한 시간 동안 증발법으로 하였다. 패터닝한 ITO 기판은 이소프로필 알코올을 이용해 $50^{\circ} \mathrm{C}$ 의 온도에서 한 시간 동안 초음파 세척하였으며 (Branson 2210R-DTH), 다 음으로 증류수를 이용해 같은 방식으로 세척하였다. 세척이 끝나면 질소 기체로 기판을 건조시켰다.

정공 수송층으로는 $\mathrm{TPD}$ 를 사용하였고, 발광 및 전 자 수송층으로 $\mathrm{Alq}_{3}$ 를 사용하였다. 전자 주입을 강화 하기 위한 버퍼층으로는 lithium fluoride $(\mathrm{LiF})$ 를 사 용하였다 [6,7]. 또한, 강한 전자 친화도를 가지는 $\mathrm{TCNQ}$ 를 정공 수송층에 도핑하거나 ITO 전극 위에 박막층을 형성하여 소자를 제작하였다. 그림 1 은 $\mathrm{TCNQ}$ 의 분자 구조를 보여주고 있다. 이 물질은 강한 전자 끌게 특성을 가지고 있으며, 이는 방향족기인

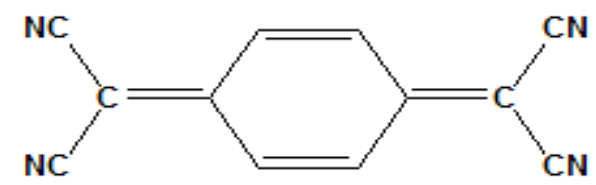

Fig. 1. Molecular structure of TCNQ.

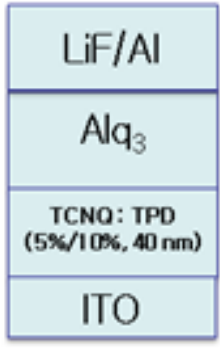

Device A

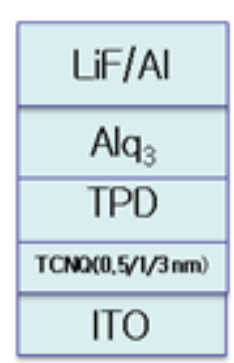

Device B
Fig. 2. Device structures used in our study.

시아노기(cyano group : $\mathrm{CN}$ )와 결합함으로서 나타난 특성이다.

그림 2는 본 연구에서 사용한 소자들의 구조이다. 소자 $\mathrm{A}$ 는 정공 수송층인 $\mathrm{TPD}$ 에 $\mathrm{TCNQ}$ 를 도핑하여 전기 전도도, 정공 주입 및 수송에 변화를 주고자 하 였다. 도핑 농도는 5 와 $10 \mathrm{vol} \%$ 로 하였으며, 도핑 농 도는 $\mathrm{TPD}$ 와 $\mathrm{TCNQ}$ 의 증착 속도를 다르게 하여 동시 에 증착하는 방법으로 조절하였다. 소자 $\mathrm{B}$ 는 $\mathrm{ITO}$ 와 $\mathrm{TPD}$ 층 사이에 $\mathrm{TCNQ}$ 층을 $0.5 \mathrm{~nm}, 1 \mathrm{~nm}$, 그리고 $3 \mathrm{~nm}$ 로 삽입하여 제작하였다.

$\mathrm{TPD}$ 와 $\mathrm{Alq}_{3}$ 는 $10^{-6}$ torr의 압력 하에서 $1.0 \sim 1.5$ $\AA / \mathrm{s}$ 의 증착 속도로 각각 $40 \mathrm{~nm}$ 와 $60 \mathrm{~nm}$ 를 열증착하 였다. $\mathrm{TCNQ}$ 는 같은 압력 하에서 $0.2 \sim 0.5 \AA / \mathrm{s}$ 로 열 증착하였다. $\mathrm{LiF}$ 는 $0.2 \AA / \mathrm{s}$ 의 속도로 열증착하여, 0.5 $\mathrm{nm}$ 의 두께를 형성하였다. 그리고 나서 알루미늄 $(\mathrm{Al})$ 음전극은 $100 \mathrm{~nm}$ 의 두께로 열증착하였으며, ITO와 $\mathrm{Al}$ 전극이 중첩된 소자의 발광 면적은 $3 \times 5 \mathrm{~mm}^{2}$ 가 되도록 하였다. 제작한 소자의 전압-전류 밀도 특성 과 전압-휘도 특성은 Keithley 236 source-measure unit, Keithley 617 electrometer, 그리고 $\mathrm{Si}$ 광 다이오 드를 이용하여 측정하였다.

\section{3. 결과 및 고찰}

그림 3 은 정공 수송층인 $\mathrm{TPD}$ 에 $\mathrm{TCNQ}$ 를 5 와 10 

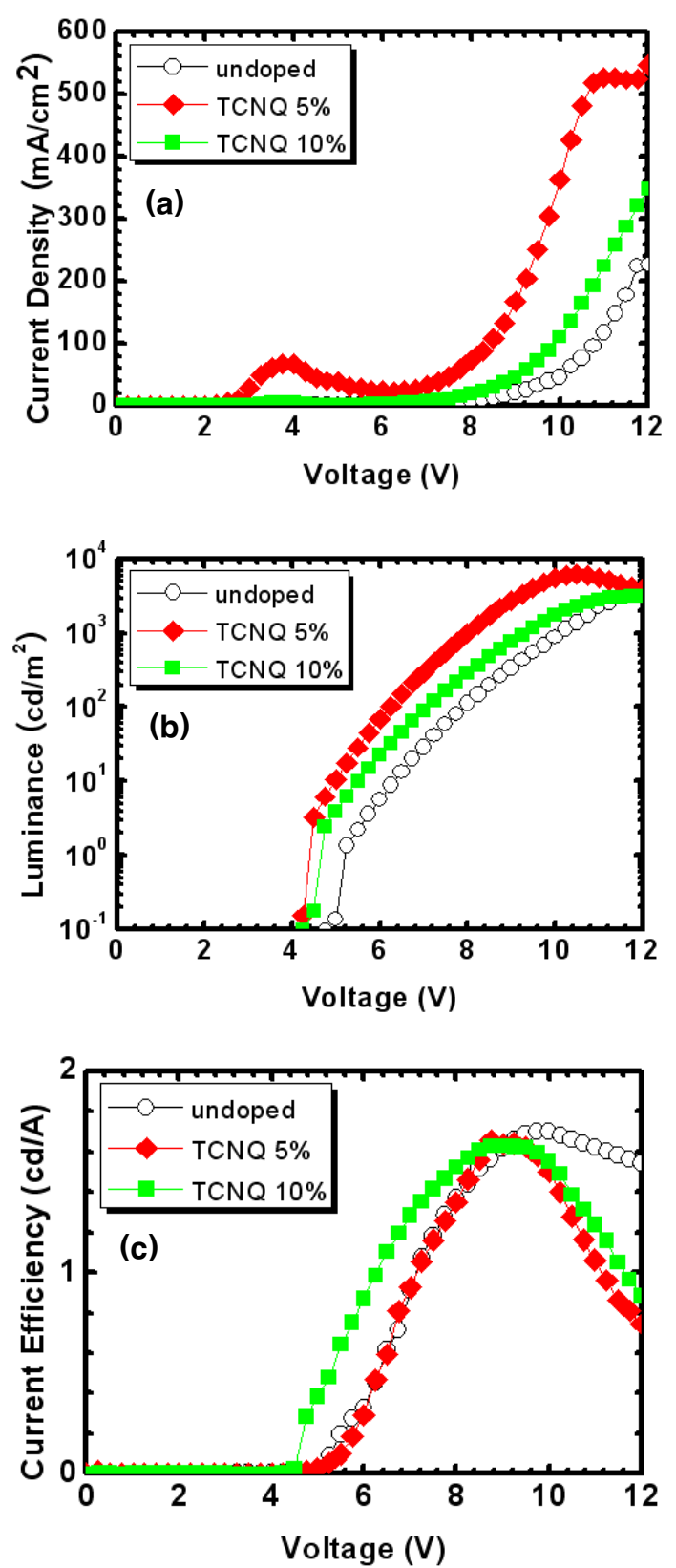

Fig. 3. Electroluminescent properties of ITO/ TCNQ:TPD/Alq3/LiF/Al devices with 5 and $10 \%$ of TCNQ doped to hole-transport layer of TPD Voltagedependent; (a) current density, (b) luminance and (c) current efficiency.

$\mathrm{vol} \%$ 로 도핑한 $\mathrm{ITO} / \mathrm{TCNQ}: \mathrm{TPD} / \mathrm{Alq}_{3}(60 \mathrm{~nm}) / \mathrm{LiF}$ $(0.5 \mathrm{~nm}) / \mathrm{Al}$ 소자의 (a) 전압-전류 밀도 특성, (b) 전 압-휘도 특성, 그리고 (c) 전압-전류 효율 특성 곡선 이다. 그림 3(a)의 전압-전류 밀도 특성을 보면, 인가
Table 1. Electroluminescent properties of ITO/ TCNQ:TPD/Alq $/ \mathrm{LiF} / \mathrm{Al}$ devices with 5 and $10 \%$ of TCNQ doped to TPD.

\begin{tabular}{c|c|c|c}
\hline TCNQ:TPD & undoped & $5 \%$ & $10 \%$ \\
\hline \hline $\begin{array}{c}\text { Driving Voltage [V] } \\
@ 100 \mathrm{~mA} / \mathrm{cm}^{2}\end{array}$ & 10.8 & 8.50 & 9.85 \\
\hline $\begin{array}{c}\text { Driving Voltage [V] } \\
@ 100 \mathrm{~cd} / \mathrm{m}^{2}\end{array}$ & 7.90 & 6.25 & 7.10 \\
\hline $\begin{array}{c}\text { Current Density } \\
{\left[\mathrm{mA} / \mathrm{cm}^{2}\right]}\end{array}$ & 7.50 & 22.0 & 7.50 \\
$@ 100 \mathrm{~cd} / \mathrm{m}^{2}$ \\
\hline $\begin{array}{c}\text { Current Efficiency } \\
{[\mathrm{cd} / \mathrm{A}]}\end{array}$
\end{tabular}

전압이 증가함에 따라 전류 밀도가 비선형적으로 증 가함을 알 수 있다. $\mathrm{TCNQ}$ 를 $5 \%$ 도핑한 소자의 경우, 전류 밀도가 다른 소자에 비해서 더 많이 흐르는 것으 로 나타났다. 그러나 $\mathrm{TCNQ}$ 를 $10 \%$ 도핑한 소자의 인 가 전압에 따른 전류 밀도는 $5 \%$ 도핑한 소자보다 줄 어들고 도핑하지 않은 소자보다는 약간 큰 값을 보이 고 있다. 그림 3(b)는 인가 전압에 따른 휘도를 나타 내고 있다. $\mathrm{TCNQ}$ 를 $5 \%$ 도핑한 소자는 도핑하지 않 은 소자에 비해 turn-on 전압이 약 $5.2 \mathrm{~V}$ 에서 $4.2 \mathrm{~V}$ 로 낮아지고, 휘도 또한 증가함을 알 수 있다. 그림 3(c)는 인가 전압에 따른 전류 효율을 나타내고 있다. 전반적으로 볼 때, 인가 전압이 증가함에 따라 전류 효율이 증가하여 약 $9 \mathrm{~V}$ 에서 최대 효율 $1.7 \mathrm{~cd} / \mathrm{A}$ 에 도달한다. $4 \mathrm{~V}$ 와 $9 \mathrm{~V}$ 사이에서 $10 \%$ 도핑한 소자의 효율이 도핑하지 않거나 5\% 도핑한 소자의 효율보다 크게 나타났다. 예를 들어 인가 전압이 $6 \mathrm{~V}$ 인 경우, 도핑하지 않은 소자의 효율 $0.3 \mathrm{~cd} / \mathrm{A}$ 에서 $\mathrm{TCNQ}$ $10 \%$ 도핑함으로 인해 $0.9 \mathrm{~cd} / \mathrm{A}$ 로 약 세 배 증가하는 효과를 얻었다. $9 \mathrm{~V}$ 이상의 전압에서는 도핑하지 않 은 소자의 전류 효율이 도핑한 소자에 비해 다소 완 만하게 감소함을 알 수 있다. 이러한 결과를 표 1 에 정리하여 나타내었다. 

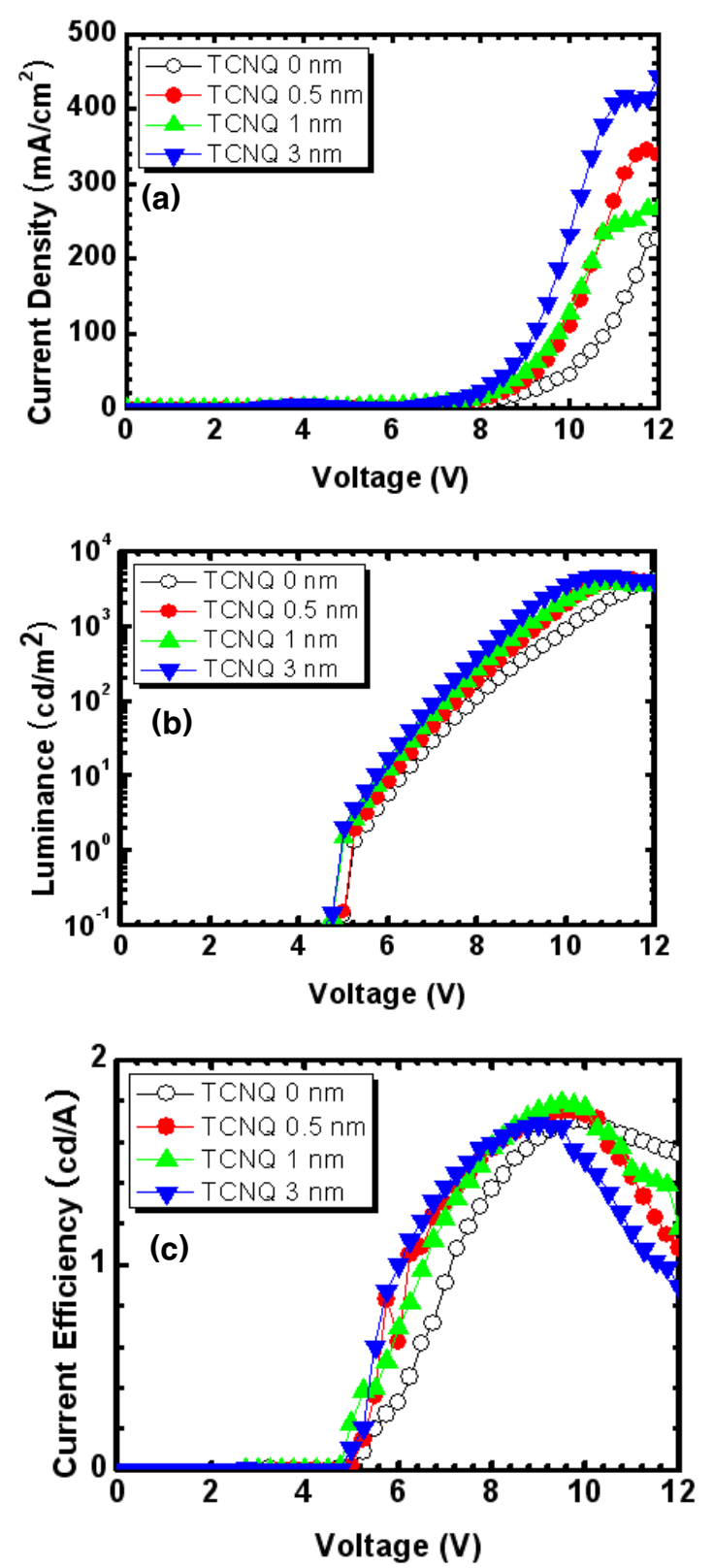

Fig. 4. Electroluminescent properties of ITO/ $\mathrm{TCNQ} / \mathrm{TPD} / \mathrm{Alq}_{3} / \mathrm{LiF} / \mathrm{Al}$ devices with TCNQ inserted between ITO and TPD layer. Voltage-dependent (a) current density, (b) luminance and (c) current efficiency.

이러한 현상은 강한 전자 끌게 특성을 가진 $\mathrm{TCNQ}$ 에 의해 $\mathrm{TCNQ}: \mathrm{TPD}$ 층의 전도도가 향상되어, 정공 수송층에서의 전압 강하가 줄어들어 일어난 현상으로 판단된다. 약 $9 \mathrm{~V}$ 이상에서 전류 효율은 도핑한 소자 에 비해 도핑하지 않은 소자가 더 높게 나타났는데, 이는 $\mathrm{TCNQ}$ 에 의해 정공의 주입이 활발히 일어나지
Table 2. Electroluminescent properties of ITO/ $\mathrm{TCNQ} / \mathrm{TPD} / \mathrm{Alq}_{3} / \mathrm{LiF} / \mathrm{Al}$ devices with $\mathrm{TCNQ}$ inserted between ITO and TPD layer.

\begin{tabular}{|c|c|c|c|}
\hline TCNQ:TPD & $0 \mathrm{~nm}$ & $0.5 \mathrm{~nm}$ & $1 \mathrm{~nm}$ \\
\hline $\begin{array}{l}\text { Driving Voltage [V] } \\
\quad @ 100 \mathrm{~mA} / \mathrm{cm}^{2}\end{array}$ & 10.8 & 9.95 & 9.75 \\
\hline $\begin{array}{l}\text { Driving Voltage [V] } \\
\text { (a) } 100 \mathrm{c} \mathrm{d} / \mathrm{m}^{2}\end{array}$ & 7.90 & 7.55 & 7.30 \\
\hline $\begin{array}{c}\text { Current Density } \\
{\left[\mathrm{mA} / \mathrm{cm}^{2}\right]} \\
\text { @ } 100 \mathrm{~cd} / \mathrm{m}^{2}\end{array}$ & 7.50 & 7.00 & 7.50 \\
\hline $\begin{array}{c}\text { Current Efficiency } \\
{[\mathrm{cd} / \mathrm{A}]} \\
\text { @ } 100 \mathrm{~cd} / \mathrm{m}^{2}\end{array}$ & 1.35 & 1.46 & 1.34 \\
\hline $\begin{array}{l}\text { External Quantum } \\
\text { Efficiency [\%] } \\
\text { @ } 100 \mathrm{~cd} / \mathrm{m}^{2}\end{array}$ & 0.15 & 0.16 & 0.15 \\
\hline $\begin{array}{l}\text { Maximum Current } \\
\text { Efficiency }[\mathrm{cd} / \mathrm{A}]\end{array}$ & $\begin{array}{ll} & 1.70 \\
\text { @ } & 10.0 \mathrm{~V}\end{array}$ & $\begin{array}{l}1.75 \\
\text { @ } 9.75 \mathrm{~V}\end{array}$ & $\begin{array}{c}1.79 \\
\text { (a) } 9.50 \mathrm{~V}\end{array}$ \\
\hline
\end{tabular}

만 발광층에서의 정공과 전자의 전하 불균형으로 인 해 전류 효율이 감소한 것으로 예상된다.

그림 4 는 $\mathrm{TCNQ}$ 층을 $0.5,1$, 그리고 $3 \mathrm{~nm}$ 의 두께 로 변화시키면서 $\mathrm{ITO}$ 와 $\mathrm{TPD}$ 층 사이에 삽입한 $\mathrm{ITO} / \mathrm{TCNQ} / \mathrm{TPD}(40 \mathrm{~nm}) / \mathrm{Alq}_{3}(60 \mathrm{~nm}) / \mathrm{LiF}(0.5 \mathrm{~nm}) / \mathrm{Al}$ 소자의 (a) 전압-전류 밀도 특성, (b) 전압-휘도 특 성, 그리고 (c) 전압-전류 효율 특성 곡선이다. 그림 4(a)와 4(b)를 보면, TCNQ 층의 두께가 두꺼워질수 록 전류 밀도와 휘도가 증가함을 알 수 있다. 특히, $\mathrm{TCNQ}$ 층을 $0.5 \mathrm{~nm}$ 정도로 얇게 삽입하여도 삽입하 지 않은 소자에 비해 전류가 더 잘 흐르며, TCNQ 층의 두께가 두꺼워질수록 그 효과는 더욱 두드러진 다. 그림 4(b)를 보면, TCNQ 층이 있는 소자는 두께 에 상관없이 turn-on 전압이 거의 $4.8 \sim 5 \mathrm{~V}$ 임을 알 수 있다. 그림 4(c)를 보면 알 수 있듯이 전류 효율은 약 $4.8 \mathrm{~V}$ 에서 증가하기 시작하여, 약 $9.5 \mathrm{~V}$ 에서 최대 효율 $1.8 \mathrm{~cd} / \mathrm{A}$ 의 값을 갖는다. $\mathrm{TCNQ}$ 층에 따른 효율 변화를 $6 \mathrm{~V}$ 에서 살펴보면, $\mathrm{TCNQ} 3 \mathrm{~nm}$ 인 소자의 효 율은 $1.0 \mathrm{~cd} / \mathrm{A}$ 로서 $\mathrm{TCNQ}$ 층이 없을 때의 $0.3 \mathrm{~cd} / \mathrm{A}$ 에 비하여 세 배 이상의 효율 증가가 있음을 알 수 있다. 이러한 결과를 표 2에 정리하여 나타내었다.

따라서, $\mathrm{TCNQ}$ 층을 $\mathrm{ITO}$ 와 $\mathrm{TPD}$ 층 사이에 삽입 
할 때 turn-on 전압을 거의 낮추지는 못하지만 효율 을 향상시킬 수 있음을 알았다. 이는 TCNQ 층에서 의 전압 강하는 매우 적으면서, 정공의 주입을 도와 주는 역할을 하는 것으로 판단된다.

\section{4. 결 론}

본 연구에서는 강한 전자 끌게 특성을 가진 $\mathrm{TCNQ}$ 를 사용하여 유기 발광 소자의 전기적 특성 변화를 연구하였다. 소자의 기본 구조는 $\mathrm{ITO} / \mathrm{TPD} / \mathrm{Alq}_{3} / \mathrm{LiF} /$ $\mathrm{Al}$ 으로 하였으며, $\mathrm{TCNQ}$ 를 정공 수송층인 $\mathrm{TPD}$ 에 도 핑하였을 때와 $\mathrm{ITO}$ 와 $\mathrm{TPD}$ 사이에 독립층으로 하였 을 때의 소자 특성을 연구하였다. TCNQ를 $\mathrm{TPD}$ 에 $10 \mathrm{vol} \%$ 도핑함으로서, 소자의 turn-on 전압을 20\% 감소시키고 효율을 약 세 배 향상시킬 수 있었다. 반면에 TCNQ $0.3 \mathrm{~nm}$ 를 $\mathrm{ITO}$ 전극과 $\mathrm{TPD}$ 층 사 이에 독립층으로 사용한 소자는 turn-on 전압의 감소 효과는 미미하고 효율은 세 배 이상 향상됨을 알았다. 이는 $\mathrm{TCNQ}$ 를 $\mathrm{TPD}$ 에 도핑함으로서 $\mathrm{TCNQ}: \mathrm{TPD}$ 층 의 전도도가 향상되어 정공 수송층에서의 전압 강하 가 줄어들어 turn-on 전압이 감소하고, 전하 주입이 원활히 일어나서 효율이 향상된 것으로 판단된다. 이 러한 연구를 통하여 우수한 유기 발광 소자의 특성 향상에 기여할 수 있으리라 판단된다.

\section{감사의 글}

이 논문은 2009학년도 홍익대학교 학술연구진흥비 에 의하여 지원되었음.

\section{REFERENCES}

[1] C. W. Tang and S. A. VanSlyke, Appl. Phys. Lett. 51, 913 (1987).

[2] C. Williams, S. Lee, J. Ferraris, and A. A. Zakhidov, Journal of Luminescence 110, 396 (2004).

[3] M. K. Fung, K. M. Lau, S. L. Lai, C. W. Law, M. Y. Chan, C. S. Lee, and S. T. Lee, J. Appl. Phys. 104, 034509 (2008).

[4] X. Zhou, J. Blochwitz, M. Pfeiffer, A. Nollau, T. Fritz, and K. Leo, Adv. Funct. Mater. 11, 310 (2001).

[5] M. A. Khan, W. Xu, Khizar-ul-Haq, Yu Bai, X. Y. Jiang, and Z. L. Zhang, Semicond. Sci. Technol. 23, 055014 (2008).

[6] L. S. Hung, C. W. Tang, and M. G. Mason, Appl. Phys. Lett. 70, 152 (1997).

[7] L. S. Hung, C. W. Tang, M. G. Mason, P. Raychaudhuri, and J. Madathil, Appl. Phys. Lett. 78, 544 (2001). 